\title{
Advanced medical interventions in pleural disease
}

\author{
Rahul Bhatnagar ${ }^{1,9}$, John P. Corcoran ${ }^{2,3,9}$, Fabien Maldonado4, \\ David Feller-Kopman ${ }^{5}$, Julius Janssen ${ }^{6}$, Philippe Astoul ${ }^{7}$ and \\ Najib M. Rahman $2,3,8$
}

Number 2 in the Series "Pleural Diseases"
Edited by Najib Rahman and loannis Psallidas

Affiliations: ${ }^{1}$ Academic Respiratory Unit, University of Bristol, Bristol, UK. ${ }^{2}$ Oxford Centre for Respiratory Medicine, Oxford University Hospitals NHS Trust, Oxford, UK. ${ }^{3}$ University of Oxford Respiratory Trials Unit, Churchill Hospital, Oxford, UK. " Division of Allergy, Pulmonary and Critical Care Medicine, Vanderbilt-Ingram Cancer Center, Vanderbilt University School of Medicine, Nashville, TN, USA. ${ }^{5}$ Division of Pulmonary and Critical Care Medicine, John Hopkins University, Baltimore, MD, USA. ${ }^{6}$ Department of Pulmonary Diseases, Canisius Wilhelmina Hospital, Nijmegen, The Netherlands. ${ }^{7}$ Department of Thoracic Oncology, Pleural Diseases and Interventional Pulmonology, Hôpital Nord, Aix-Marseille University, Marseille, France. ${ }^{8} \mathrm{NIHR}$ Oxford Biomedical Research Centre, University of Oxford, Oxford, UK. ${ }^{9}$ These authors contributed equally.

Correspondence: John P. Corcoran, Oxford Centre for Respiratory Medicine, Churchill Hospital, Oxford, OX3 7LE, UK. E-mail: jpcorcorandadoctors.org.uk

ABSTRACT The burden of a number of pleural diseases continues to increase internationally. Although many pleural procedures have historically been the domain of interventional radiologists or thoracic surgeons, in recent years, there has been a marked expansion in the techniques available to the pulmonologist. This has been due in part to both technological advancements and a greater recognition that pleural disease is an important subspecialty of respiratory medicine. This article summarises the important literature relating to a number of advanced pleural interventions, including medical thoracoscopy, the insertion and use of indwelling pleural catheters, pleural manometry, point-of-care thoracic ultrasound, and image-guided closed pleural biopsy. We also aim to inform the reader regarding the latest updates to more established procedures such as chemical pleurodesis, thoracentesis and the management of chest drains, drawing on contemporary data from recent randomised trials. Finally, we shall look to explore the challenges faced by those practicing pleural medicine, especially relating to training, as well as possible future directions for the use and expansion of advanced medical interventions in pleural disease.

0 @ERSpublications

Technological advances and greater availability of techniques give a broad range of interventions for pleural disease http://ow.ly/ZNya2

\section{Introduction}

The definition of an "advanced medical intervention" will undoubtedly be subject to debate and a great deal of geographical variation. Amongst respiratory physicians, the ability to perform simple pleural procedures

Editorial comment in Eur Respir Rev 2016; 25: 108-109.

Previous articles in this series: No. 1: Psallidas I, Kalomenidis I, Porcel JM, et al. Malignant pleural effusion: from bench to bedside. Eur Respir Rev 2016; 25: 000-000.

Received: Feb 292016 | Accepted after revision: March 172016

Conflict of Interest: Disclosures can be found alongside the online version of this article at err.ersjournals.com

Provenance: Submitted article, peer reviewed.

Copyright OERS 2016. ERR articles are open access and distributed under the terms of the Creative Commons Attribution Non-Commercial Licence 4.0. 
has traditionally been a core requirement for both training and general practice, with more invasive techniques typically reserved for thoracic surgery or interventional radiology colleagues. Recent years have seen rapid and unprecedented improvements to both bedside medical technology and its availability to the general physician, leading to less distinction in which procedures are performed by which group. Coupled with an increasing recognition of pleural disease as an important and distinct subspecialty [1], and the rise of the "interventional pulmonologist", tools such as thoracoscopes, indwelling pleural catheters (IPCs) and point-of-care ultrasound are now increasingly commonplace in respiratory clinics worldwide [2]. The importance of this shift cannot be overstated: patients in many centres are now offered more rapid access to diagnosis and treatment [3], with yields and safety levels akin to those provided by other specialties $[4,5]$.

Rates of many common pleural diseases, such as malignant effusions and empyema, continue to increase [6-8]. For this reason, it is vital that knowledge of novel pleural techniques is disseminated as widely and as efficiently as possible. The aim of this review is therefore to bring the reader up to date with recent advances in the interventional aspects of pleural medicine, with as much focus as possible on what can be translated to usual, day-to-day practice. The following paragraphs will cover patient selection, medical thoracoscopy and pleural biopsy, temporary drainage procedures for both air and fluid, and how to optimise them, as well as the increasing role of ambulatory care and IPCs.

\section{Patient selection}

Appropriate patient selection is a necessary part of any investigative process. It is vital to ensure that any procedure offered to a patient is in their best interests, and not, as may be the temptation, simply because it is technically possible. Maintaining a clear and coherent dialogue with patients is key and this may require additional time be allotted to traditionally short consultations. A holistic assessment will entail a thorough exploration of the patient's wishes, as well as their likely ability to cope physically with both the suggested investigation and any recovery period that may be required. In the case of ambulatory devices, such as IPCs or Heimlich valves, close consideration should also be made to a patient's social and psychological context, especially as such devices may require help from family/other caregiver, and management over extended time periods. In addition, depending on the nature of the healthcare environment, the financial costs of an intervention both in the long and short term may have to be factored in when choosing the most appropriate management course.

From a practical point of view, assessing a patient as close to the date of a procedure as possible is likely to minimise the chances of an intervention needing to be cancelled. In the case of medical thoracoscopy especially, early patient assessment and ultrasound confirmation of fluid in the lateral decubitus position can be particularly beneficial, although some centres are now able to offer on-table alternatives to thoracoscopic biopsy if required [9]. Ultimately, the specifics of which patients are felt to be suitable for which procedures will be a local decision, factoring in centre facilities and operator experience alongside the patient aspects mentioned above.

\section{Nonexpandable lung}

The early identification of those with nonexpandable lung (NEL) is an important example of how robust patient selection can dramatically alter management pathways. To describe this phenomenon, the term "trapped" lung is often used interchangeably with lung "entrapment". In general, both refer to the lung's inability to expand normally into the pleural space, although it is perhaps more precise to recognise that that the two are actually distinct entities related to specific underlying pathologies [10]. NEL may be caused by central obstructing masses but is usually a result of either localised or generalised visceral pleural thickening, typically due to chronic inflammation caused by processes such as infection or pleural malignancy [10]. The presence of NEL and the lack of pleural apposition it causes significantly increase the chances of pleurodesis failure should this be attempted [11], meaning the early use of IPCs tends to be preferred in this setting [12]. It should be noted, however, that such recommendations are based upon relatively limited evidence and by no means guarantee symptomatic benefit for patients (figure 1) [14].

The dyspnoea associated with a pleural effusion is likely to be caused by disruption to the normally efficient mechanics of the inspiratory muscles and diaphragm $[15,16]$; however, in the case of NEL, this may be relatively benign. Excessive fluid drainage in those with NEL can lead acutely to chest pain, distressing cough or a "pulling" sensation in the centre of the chest, although none of these are specific as they may also be associated with other situations, including re-expansion pulmonary oedema (REPO) [17]. Effusions related to NEL also tend to be rapidly recurrent, further supporting the use of IPCs in those with symptoms. Identification of NEL usually relies on post-procedure imaging revealing a hydropneumothorax, suggestive of a pneumothorax ex vacuo. This approach, however, requires an adequate fluid volume to be drained to reveal pathological areas. One study has suggested that, prior to invasive tests, advanced thoracic ultrasound techniques, such as M-mode and speckle tracing, may be applied to atelectatic lung in order to characterise its response to the cardiac impulse, potentially inferring the presence of NEL [19]. 

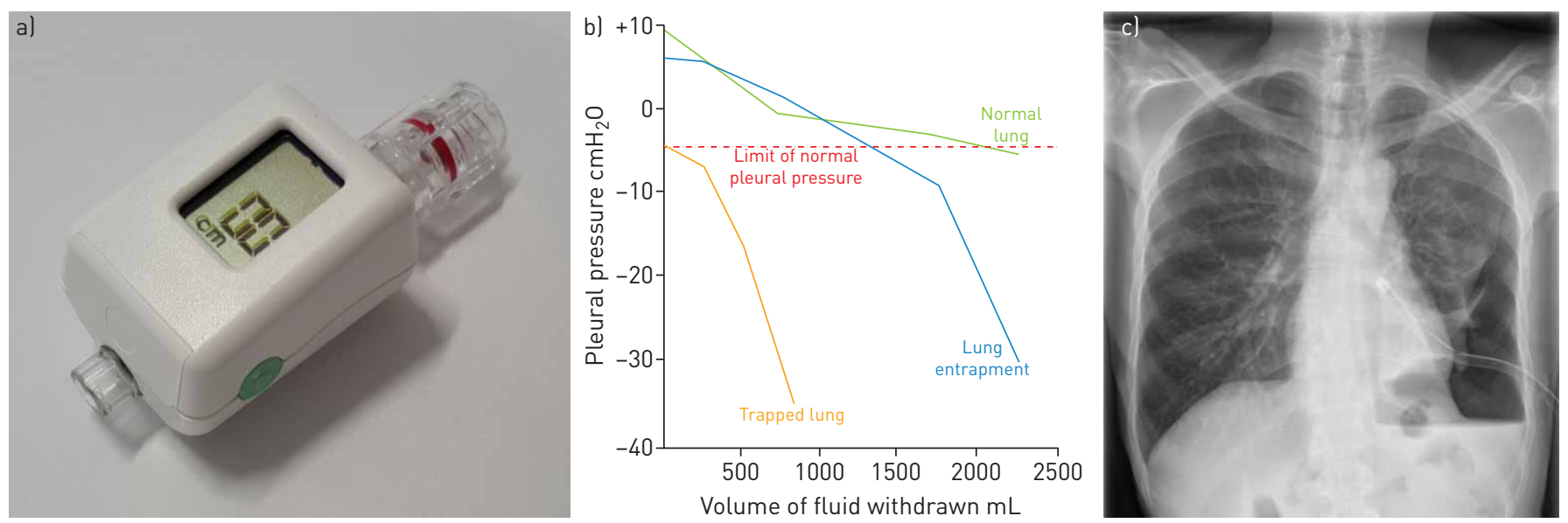

FIGURE 1 Nonexpandable lung. a) A single-use digital pleural manometer for use during thoracentesis. b) Pleural elastance curves representing normal, entrapped and trapped lung. Reproduced and modified from [13] with permission from the publisher. c) Chest radiograph demonstrating nonexpandable lung due to malignancy. A hydropneumothorax is visible at the left base with a large-bore chest drain in situ following thoracoscopy. The patient was treated with an indwelling pleural catheter.

More commonly, pleural manometry is advocated as a useful tool for characterising lung behaviour during fluid drainage. Despite there being a number of retrospective studies that have been unable to find a link between pressure readings and the development of chest discomfort [19], REPO [20] or pneumothorax ex vacuo [21], the possibility of being able to predict NEL is certainly attractive. There subsequently remains a select group of international practitioners who are strong campaigners for routine pleural manometry during thoracentesis $[22,23]$. There are those, however, who remain unconvinced [24]. Historically, one of the likely limitations to the widespread adoption of manometry has been the relatively complicated equipment required, with a reduced chance that it will be available in the routine clinic setting. Furthermore, in order to derive the elastance curves needed to infer pleural behaviour, pressure readings will usually have to be taken at frequent intervals, potentially extending the time required to perform a procedure. Recent technological advances may be able to improve the availability of manometry with single-use, small, digital manometers, which have been shown to match measurements of more established methods [25]. Elsewhere, preliminary work has been conducted to evaluate continuous [26] and high-temporal resolution pressure measurement [27], both with encouraging results.

\section{Short-term drainage procedures}

For the majority of patients, the management of pleural fluid will entail either the insertion of an intercostal chest tube or therapeutic thoracentesis. Aside from the introduction of more refined equipment, such as dedicated pleural aspiration catheters, and a move towards the use of smaller chest tubes [28], recent years have seen little meaningful change in how these procedures are performed from a technical standpoint. Nonetheless, with the increasingly widespread adoption of thoracic ultrasound to provide real-time image guidance, it could be argued that this area has been at the forefront of the most important change in pleural interventional practice for a generation.

The optimisation of drain placement and aspiration site choice has been revolutionised by point of care thoracic ultrasound. Following evidence that serious harm was being done by performing procedures "blind" [29], national guidelines now state that image guidance should be seen as best practice [30]. The practicality of this is undoubtedly challenging to deliver, placing, as it does, additional strain on both pulmonology and radiology services [31]. In response, many countries' training programmes have been adapted to ensure thoracic ultrasound is now part of the core skillset for junior pulmonologists [32-34]. The arguments for using ultrasound guidance during pleural procedures are compelling. A study performed over a decade ago was able to demonstrate that its use in comparison to clinically marked procedural sites allowed for both a greater success rate and a reduced risk of solid organ puncture, regardless of clinician seniority [35]. Such findings have been unequivocally backed up, both with meta-analysis data [36] and with a contemporary, 2-year retrospective cohort study of $>60000$ procedures demonstrating a $19 \%$ reduction in the risk of pneumothorax when thoracentesis was performed with ultrasound guidance [37]. There are also those who advocate the use of ultrasound to locate and avoid the intercostal artery prior to pleural intervention (figure 2) [38].

In those patients who present with pneumothorax as their primary pathology or in those in whom a visceral puncture is suspected, the monitoring of air leak via an intercostal chest drain is of prime 

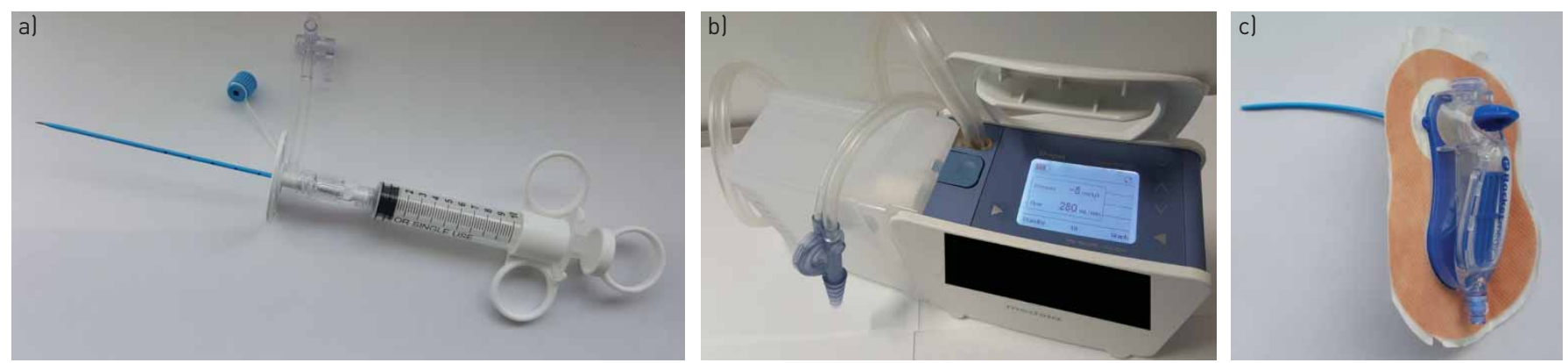

FIGURE 2 Examples of novel short-term drainage devices. a) 6-French thoracentesis catheter with integrated three-way tap. b) Chest drain bottle with integrated air leak monitor and digital suction. c) Pleural vent with integrated Heimlich valve for treatment of pneumothorax.

importance. Although initially targeted at post-thoracic surgical patients, chest drain bottles with digital air leak monitors are now increasingly available to the physician. The information they provide as to whether a leak is improving or persisting can guide further management with regards to the timing of drain removal or the need for surgical referral, respectively [39]. For some, especially those unfit for surgery with persistent secondary pneumothoraces or those looking to avoid hospital admission following a primary event, the use of a one-way (Heimlich) valve apparatus attached to a chest drain can allow greater freedom through ambulatory care [40]. New, transthoracic pleural vent devices designed for rapid and easy insertion have recently found their way to the market, with at least one randomised trial to test efficacy against standard care already in progress [41]. Using a similar study design, endobronchial one-way valves (which have been proven to be effective for the treatment of heterogeneous emphysema) [42] are also under investigation for the treatment of persistent pleural air leaks [43].

It is perhaps, however, the treatment of pleural effusions with chest drains that has seen the greatest advances in recent years. The Second Multi-Centre Intra-Pleural Sepsis Trial (MIST2), published in 2011, examined whether a combination of an intrapleural fibrinolytic (tissue plasminogen activator (t-PA)) with DNase could improve the radiographic appearances of those with pleural infection when compared to those treated with single agents or placebo [44]. The results confirmed the findings of MIST1, proving that single-agent fibrinolytic therapy had no role in this setting [45], but also demonstrated a $22 \%$ improvement in imaging appearances when dual-agent therapy was used instead of placebo. Of perhaps greater interest were the trial's secondary outcomes, which suggested a reduced surgical referral rate and reduced period of hospitalisation for those treated with the newer regimen [44]. Despite the combination group consisting of only 52 patients, there has been a great deal of enthusiasm amongst physicians for the use of t-PA/DNase; a recent retrospective series of 107 patients treated this way, drawn from around the world, suggested that even when used in a more pragmatic fashion than in the clinical trial setting, $92.3 \%$ of patients were able to avoid surgical intervention. Nonfatal bleeding was reported in $<2 \%$, although a fifth of patients required an increase in their analgesia due to chest pain [46].

The appeal of fibrinolytic treatment has also begun to extend beyond those with pleural infection. Patients with malignant pleural effusions (MPEs) are also susceptible to developing fluid septations and symptomatic loculations, a finding which can be particularly difficult to manage. A multicentre review of four pleural centres described 66 cases of fibrinolytic therapy given via an IPC for this indication. What was clear was that there is not yet a consensus on how, or indeed whether, treatment should be given to this population [47]. A recently reported randomised controlled trial (RCT), the TIME3 (Third Therapeutic Intervention in Malignant Effusion Trial) study, addressed whether treatment with urokinase via a chest drain could improve pleurodesis efficacy in loculated MPE. Although limited by under-recruitment, the results would suggest there is no benefit to this approach with respect to either patient symptoms or pleurodesis success (Eleanor Mishra and Najib Rahman, personal communication), further highlighting the need for prospective research to clarify the wider role of intrapleural fibrinolytic treatments.

Another controversy relating to MPE treatment has revolved around the theoretical interference of nonsteroidal anti-inflammatory drugs (NSAIDs) with the pleurodesis process [48]. Addressing both this and the most appropriate choice of drain size, the TIME1 study, a suitably powered, well-conducted RCT, has recently reported its findings [49]. In the trial, patients needing pleurodesis were allocated to receive either a 24-French (F) (large bore) drain or a 12F (standard small bore), in combination with either NSAID-based analgesia or a more typical opiate-based regimen. The results dispel the myth that NSAIDs have a detrimental effect on pleurodesis success but they were not found to be any better than standard opiate therapy. Perhaps more intriguingly, the study also found that those patients who had $12 \mathrm{~F}$ drains suffered from a higher proportion of complications, including unintentional displacement, and concurrently 
appeared to have a reduced chance of pleurodesis success, with $24 \mathrm{~F}$ drains not necessarily causing greater discomfort to a clinically relevant degree [49]. These results appear to oppose the trend towards the increasing use of small-bore drains and certainly ensure the debate about whether drain size influences clinical outcomes will continue.

Despite studies such as this helping to inform the future use of chest drains, there are still a great deal of unanswered questions remaining. This means that areas such as whether or not to use pleural suction; when to give a pleurodesis agent; [50] and, indeed, what actually constitutes a successful pleurodesis remain largely unaddressed.

\section{Indwelling pleural catheters}

The increasing use of IPCs is another clear example of how technological advances in pleural medicine can have a direct impact on both the care of patients and the attitudes of physicians who manage them. Introduced in 1997, IPCs are now available routinely in much of the developed world, with a number of manufacturers having developed similar products. The core principle of all these devices remains the same: a tunnelled, silicone-based, multifenestrated chest tube is inserted into a pleural effusion, most commonly MPE, under local anaesthesia and in the outpatient setting. A proprietary valve connects the system to a dedicated fluid collection system, which is usually vacuum based. Patients and carers are empowered, therefore, to manage their recurrent collections at home and, in many cases, can avoid or significantly reduce hospital admissions [51-53]. Initially recommended for the management of those patients who had failed pleurodesis $[12,54]$ or those in whom trapped lung was the primary pathology $[14,55,56]$, recent years have seen a shift in many centres towards an alternative paradigm, one in which IPCs are viewed as a valid first-line alternative to chemical sclerosant therapy [57, 58]. This idea was cemented by the publication of the TIME2 study, a multicentre RCT comparing standard chest drain and talc pleurodesis to IPC for the management of MPE. The patient-focused primary outcome of dyspnoea at 6 weeks was found to be no different between the two arms, with secondary analyses also suggesting those receiving an IPC spent less time in hospital and required fewer pleural procedures. In addition, subsequent analysis showed using an IPC was a more cost-effective strategy for those with a reduced life expectancy [59], a finding that has been replicated elsewhere [60-63]. These positive effects were balanced by a greater number of adverse events in the IPC group, although the rates of complications have been reported as significantly lower in larger, retrospective studies [64,65]. Pleurodesis rates are also routinely lower in those patients treated with IPCs $[64,66]$, although many would argue this is not the desired effect of this treatment (table 1).

It has traditionally been felt that the use of chemotherapy precludes the insertion of an IPC due to a heightened possibility of infection. This idea has not been borne out by the literature, however, with numerous studies reporting no additional risk in this circumstance [71, 72]. In fact, as international experience with IPCs continues to grow, there is an increasing number of series describing their use in scenarios beyond MPE, including haemothorax [73], chronic empyema [74] and recurrent nonmalignant effusions [75]. This latter group of patients has recently been targeted due to the particularly high incidence of effusions associated with conditions such as cardiac and hepatic failure, or renal impairment [76-78]. Although current data are limited by numbers of patients and retrospective collection, it has been suggested that the use of IPCs in the benign setting is safe in sufficiently experienced hands, albeit with reduced pleurodesis rates compared to the MPE population [79]. A RCT is currently underway in the UK to clarify this further [80].

With the primary attractions of an IPC being ambulatory care and continuous access to the pleural space, it is not surprising that research has begun to emerge that describes these benefits applied in combination

\begin{tabular}{|c|c|c|c|c|c|c|}
\hline VAN Meter [64] & 2010 & 1370 & 2.8 & 45.6 & 95.6 & 51 \\
\hline RosENSTENGEL [67] & 2012 & 1036 & 4.8 & NA & NA & NA \\
\hline SuZUKı [68] & 2011 & 418 & NA & 26 & 91 & 44 \\
\hline & & Total 3192 & Mean 3.9 & Mean 43.5 & Mean 94.2 & Mean 64.3 \\
\hline
\end{tabular}

The series by VAN METER [64] is a meta-analysis of 19 smaller studies. NA: not applicable. 
with more established treatments. A multicentre RCT exploring the outpatient administration of talc via an IPC is nearing completion [81], with one small series already reporting success locally using this approach [82]. Alternative pleurodesis agents, both established [83] and experimental [84] have also been administered this way, and some investigators have used them as a conduit for delivery of systemic compounds such as interferon- $\beta$ or docetaxel $[85,86]$. Animal studies have also suggested that pleurodesis agents may be coated onto IPCs to create drug-eluting catheters $[87,88]$. The appeal of using IPCs in these ways is likely to drive further research, especially with the promise of increasingly individualised anticancer therapy.

A conversation regarding how they wish to have their recurrent effusion managed is one of the most important, yet simultaneously conceptually difficult, discussions a patient is likely to have with their pleural physician or surgeon. The idea that there may not be a "best" treatment (what suits one patient may not be appropriate for another, and what suits a patient at one time may not suit the same patient later in their care pathway) is particularly challenging for many. As more studies relating to the novel applications of IPCs are reported, navigating this complexity is likely to become an ever more crucial part of successful pleural medicine delivery.

\section{Medical thoracoscopy and closed pleural biopsy}

The incidence of pleural effusion is rising with over 1.5 million new cases diagnosed annually in the USA alone $[30,89]$. Whilst the majority of these have a benign aetiology, it is estimated that $>250000$ will be secondary to underlying malignancy $[30,90,91]$. This burden is likely to increase in the context of an ageing population and the growing number of individuals both newly diagnosed and surviving long-term with cancer as a result of widening options for oncological intervention. As MPE is frequently associated with poorer long-term outcomes [91], identifies patients with nonresectable disease in the setting of a distal primary cancer (including lung) and commonly results in significant disabling dyspnoea, the early identification of these patients is a clinical priority. Guidelines subsequently recommend a systematic approach to the investigation of a unilateral effusion of uncertain cause [30]. This process frequently culminates in the need to obtain diagnostic pleural tissue, either in the event of initial thoracentesis being unhelpful $[92,93]$ or, as is increasingly the case, additional material being required to facilitate histological and molecular analysis that will inform a patient's continued management.

Interventional pulmonologists have two means by which to obtain diagnostic pleural tissue, closed pleural biopsy (CPB) or medical thoracoscopy. Neither of these techniques is new and both have drifted in and out of fashion over the years. However, while thoracoscopy is now widely acknowledged to be the gold standard, it is also recognised by the modern clinician advocating either one or both procedures that each has their advantages, disadvantages and place in the management of patients with pleural disease.

\section{Closed pleural biopsy}

CPB was first described by ABRAms [94] and Cope [95] in the mid-20th century as an alternative means of obtaining pleural tissue without resorting to surgical thoracotomy. Its continued use more than five decades later can be attributed to factors including ease of use, low cost and tolerability to patients. This is of particular importance in parts of the world where access (financial and geographical) to healthcare resources is limited; this frequently coincides with those areas where tuberculosis is an important cause of pleural effusion and the diffuse nature of the infective pleuritis lends itself to CPB as a diagnostic strategy [96]. There has been technical progress nonetheless, notably a move towards core-cutting rather than traditional reverse bevel needles [97, 98], and the recognition that CPB should be performed using image guidance to optimise yield and patient safety $[99,100]$.

Image-guided $\mathrm{CPB}$ was initially the domain of specialist radiologists utilising either computed tomography (CT) or ultrasound to identify and sample localised pleural thickening and/or nodularity [99-102]. More recently though, and with thoracic ultrasound competencies being incorporated into pulmonology training programmes [32-34], this technique has been successfully adopted by physicians with a diagnostic yield comparable to that obtained by radiologists $[9,103]$. The use of ultrasound guidance during CPB allows the operator to target areas of interest whilst compensating for respiratory movement in real time and avoiding the need for prolonged breath hold manoeuvres in potentially dyspnoeic patients. It has the further advantage of avoiding the exposure to ionising radiation required by CT or fluoroscopic guidance. The patient is placed in a lateral decubitus or, rarely, prone position and a low-frequency $(2-5 \mathrm{MHz})$ curvilinear probe employed to direct the core-cutting biopsy needle, having first identified any underlying at-risk structures including intercostal vessels [38] and viscera. The technique permits, in expert hands, the sampling of not only pleural abnormalities but also chest wall and peripheral lung parenchymal lesions for diagnostic purposes $[103,104]$. Whilst no formal guidelines exist, the authors would suggest performing between eight and 10 core pleural biopsies to ensure adequate sampling. Post-procedural ultrasound 
assessment can also identify complications such as pneumothorax or intrapleural haemorrhage and, if necessary, allow early directed treatment (figure 3) [105].

$\mathrm{CPB}$ has the advantage of being a procedure that is well-tolerated by patients and easily delivered by clinicians without the need for a bespoke working environment, hospital admission or support team. As a minimally invasive approach, it has been advocated as a front-line initial diagnostic test alongside thoracentesis in the undiagnosed unilateral effusion; this might preclude the need for subsequent thoracoscopy and have particular value in those areas where tuberculosis is endemic [106, 107]. Whether this diagnostic benefit can be extrapolated to areas with a low incidence of tuberculosis is less clear [92] and needs further investigation in a modern-day pleural service. CPB also offers an alternative diagnostic approach in the patient either unwilling or too frail to have a thoracoscopic procedure, or indeed when a planned thoracoscopy itself fails [9]. Complication rates are low, with pain, bleeding and pneumothorax being seen in $<5 \%$ of cases $[9,99,103,107]$; this usually facilitates day-case management with a short period of observation post-procedure. Nonetheless, it is a purely diagnostic procedure and, unlike thoracoscopy, does not offer any therapeutic or symptomatic gain to the patient. The quantity of tissue that can be obtained by CPB is also limited by comparison with a thoracoscopic approach; this may
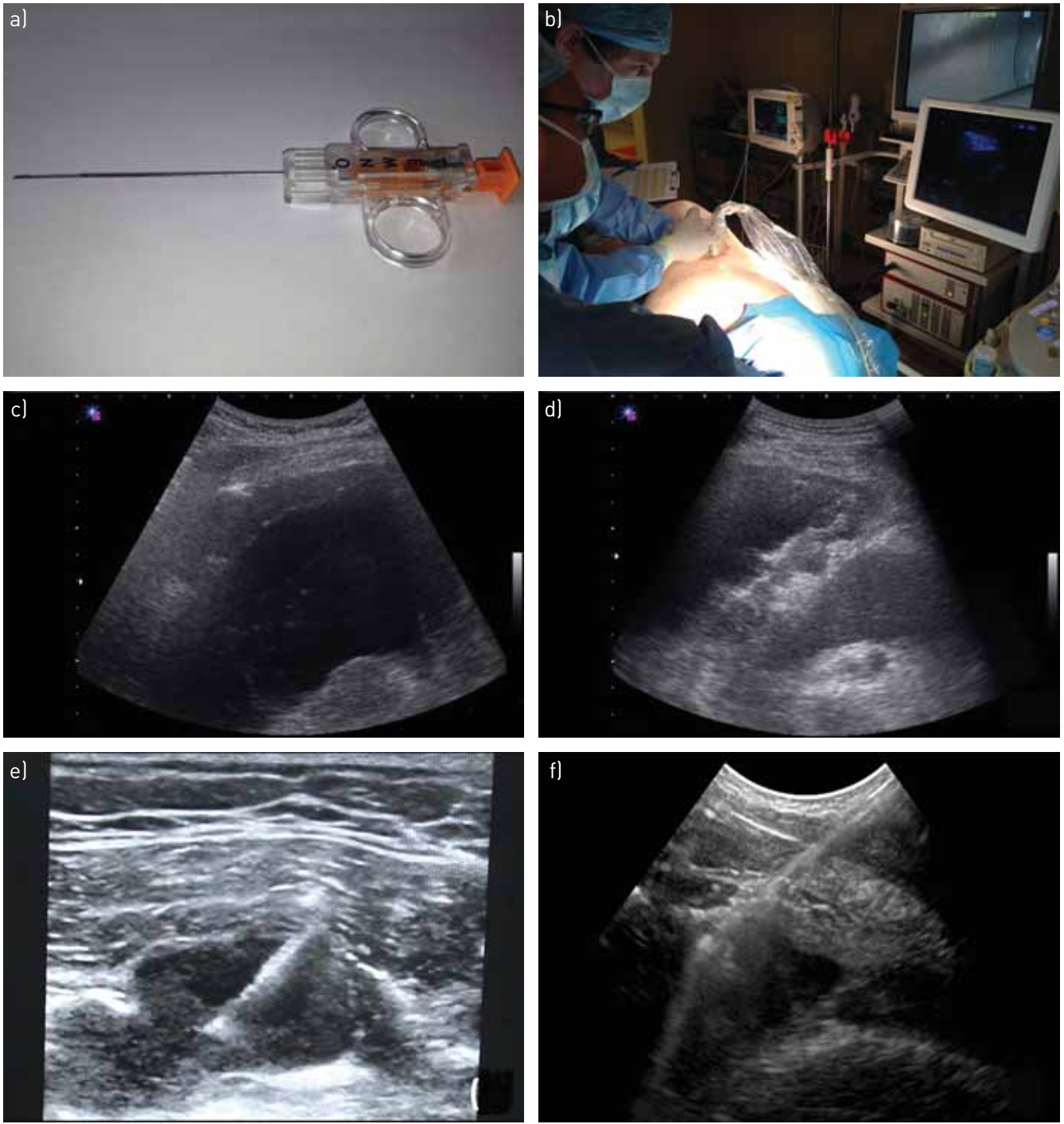

FIGURE 3 Closed pleural biopsy. a) Example of a core-biopsy cutting needle. b) Example of procedural room set-up with operator line of sight and in-plane real-time ultrasound guidance. c) Ultrasound view of irregular parietal pleural thickening with effusion. d) Ultrasound view of irregular diaphragmatic and parietal pleural thickening with effusion. e) High-frequency $(10 \mathrm{mHz})$ real-time ultrasound-guided cutting needle biopsy of pleural and chest wall mass. f) Low frequency $(3.5 \mathrm{mHz})$ real-time ultrasound-guided cutting needle biopsy of parietal pleural thickening. 
impact negatively on those cases where additional molecular analysis is required or histological diagnosis can be particularly challenging (e.g. mesothelioma).

\section{Medical thoracoscopy}

The first published report of a thoracoscopic intervention dates back to 1866 when Cruise and GoRDON [108] utilised a urological endoscope in the treatment of a pleural empyema at the Mater Misericordiae Hospital in Dublin, Ireland. However, it is JACOBAeus $[109,110]$ who is widely regarded as the father of thoracoscopy, having published widely on the technique and its different indications over three decades in the early 20th century; in particular, the artificial induction of pneumothorax and division of pleural adhesions in order to treat tuberculosis. The discovery of antituberculous agents such as streptomycin in the 1950s led to a rapid decline in the use of thoracoscopy; it was not until the late 1980s when advances in miniature camera, fibreoptic and video technology allowed the technique to be revived. Thoracoscopy has grown steadily in popularity ever since, with both thoracic surgeons and pulmonologists offering the procedure due to its combined diagnostic and therapeutic capabilities.

Although a clear distinction should be made between medical thoracoscopy (i.e. physician-led procedures) and thoracic surgical intervention, it is important to recognise that interventional pulmonologists are performing increasingly complex thoracoscopic interventions, including those under general anaesthesia, on a regular basis. The available data suggest that medical thoracoscopy is a safe procedure with a mortality rate of $<1 \%$, generally associated with the use of insufflated talc as a therapeutic agent, and a low risk $(<10 \%)$ of peri-procedural morbidity or complications [111].

\section{Technical considerations}

As outlined earlier in this review article, appropriate patient selection is critical prior to embarking on any interventional procedure. There are published guidelines addressing this subject area along with the facilities and support staff necessary to deliver a safe and efficient thoracoscopy service [111]. Although the majority of physicians perform thoracoscopy under local anaesthetic and analgosedation, it is worth noting that some larger specialist units also offer a general anaesthetic service that in turn facilitates more complex interventions. The presence of anaesthetic support also allows selective intubation and lung isolation, facilitating positive-pressure inflation of the collapsed lung under thoracoscopic vision prior to talc poudrage. This may allow the identification of NEL and contemporaneous insertion of an IPC to allow a single-step complete management strategy.

The choice of sedative agent(s) during thoracoscopy should be made on a case-by-case basis and determined by operator experience, patient characteristics and the nature of the procedure to be undertaken [112]. The patient is placed in the lateral decubitus position and a detailed ultrasound examination performed to determine both the underlying anatomy and point of access that will maximise the likelihood of procedural success $[113,114]$. A trocar and port are introduced following blunt dissection of the chest wall (analogous to large-bore surgical chest drain insertion), usually in the fourth to sixth intercostal space between the mid- and anterior axillary line. The pleural fluid is then evacuated completely using a suction catheter before inserting the thoracoscope and inspecting the thoracic cavity thoroughly.

Successful thoracoscopy is dependent on having an adequate working space both to manipulate instruments and to allow full visualisation of the thoracic cavity, since abnormalities may be subtle and/or highly localised: early metastatic deposits frequently favour a posterobasal location and, consequently, the pleural space cannot be cleared without careful inspection of the paraspinal gutter and diaphragmatic recesses. Gaining access to the thoracic cavity is relatively straightforward in the context of a moderate to large pleural effusion; however, the absence of any pleural fluid should not be considered a barrier to medical thoracoscopy. Assuming significant pleural adhesions are excluded through the confirmation of lung sliding on ultrasound, pneumothorax induction can then be safely performed using either blunt dissection or Boutin needle introduction under real-time ultrasound visualisation $[115,116]$. Following a complete inspection of the thoracic cavity, biopsies of the parietal pleura are then obtained; the authors would advise taking multiple biopsies from different sites to maximise the probability of a secure diagnosis. In the specific context of suspected mesothelioma with diffuse parietal pleural thickening on macroscopic inspection, deep "strip" biopsies should be obtained down to the level of periosteum in order to limit any diagnostic uncertainty on subsequent histological examination. Rapid on-site evaluation of thoracoscopic biopsies may reduce the likelihood of nondiagnostic interventions, as has been the case in endobronchial ultrasound and mediastinal node sampling [117], but as yet, there are no published data to support this conclusion (figure 4).

The majority of published data on medical thoracoscopy relate to procedures utilising a rigid thoracoscope. However, there is a growing body of interventional pulmonologists who favour a semirigid 
instrument as a result of its increased flexibility, familiarity of use and compatibility with existing equipment due to the similarities with flexible bronchoscopes. There are limited data comparing the diagnostic yield of pleural biopsies taken using either a rigid or semirigid thoracoscope, although what has been published has not identified a significant difference between these techniques [118-119]. The authors tend to favour rigid thoracoscopy: besides than the larger working channel and ability to obtain larger biopsies that this approach offers, there is also the option to convert to a two-port technique that facilitates more complex procedures such as extended adhesiolysis. Nonetheless, it is less of an issue whether a rigid or semirigid thoracoscopic approach is utilised, and more important that the procedure is done well and safely. With respect to this, there is no formal guideline available as yet that specifically details training standards for medical thoracoscopy; given its increasing use the development of this resource should be regarded as a priority in the near future $[111,121]$.

\section{Undiagnosed pleural effusion and MPE}

Medical thoracoscopy is well established as a key diagnostic test in the investigation of an exudative pleural effusion of unknown cause [30], with excellent sensitivity and specificity in both tuberculous and malignant effusions where previous less invasive investigations have failed to yield the diagnosis [111]. Up to a third of patients with an exudative effusion will be diagnosed with nonspecific pleuritis/fibrosis (NSP) on thoracoscopic biopsies; in these circumstances, the authors recommend a minimum of 2 years' clinical and imaging follow-up due to the risk of developing malignancy at a later stage ( $10 \%$ of cases of NSP), particularly mesothelioma $[4,122,123]$.

In contrast to techniques such as $\mathrm{CPB}$ or tube thoracostomy, thoracoscopy permits a combined diagnostic and therapeutic procedure. Complete drainage of large-volume effusions is feasible with a low risk of complications such as REPO [111, 124], facilitating an immediate pleurodesis. In physician-led procedures, this is most commonly performed using a poudrage of sterile graded large-particle talc. Whether this particular method of pleurodesis has a therapeutic advantage in established MPE over traditional talc slurry following tube thoracostomy remains unanswered by the currently available data [125, 126], although a large-scale RCT is currently underway with the aim of answering this important clinical question [127]. Some clinicians have proposed the placement of an IPC at the same time as thoracoscopy
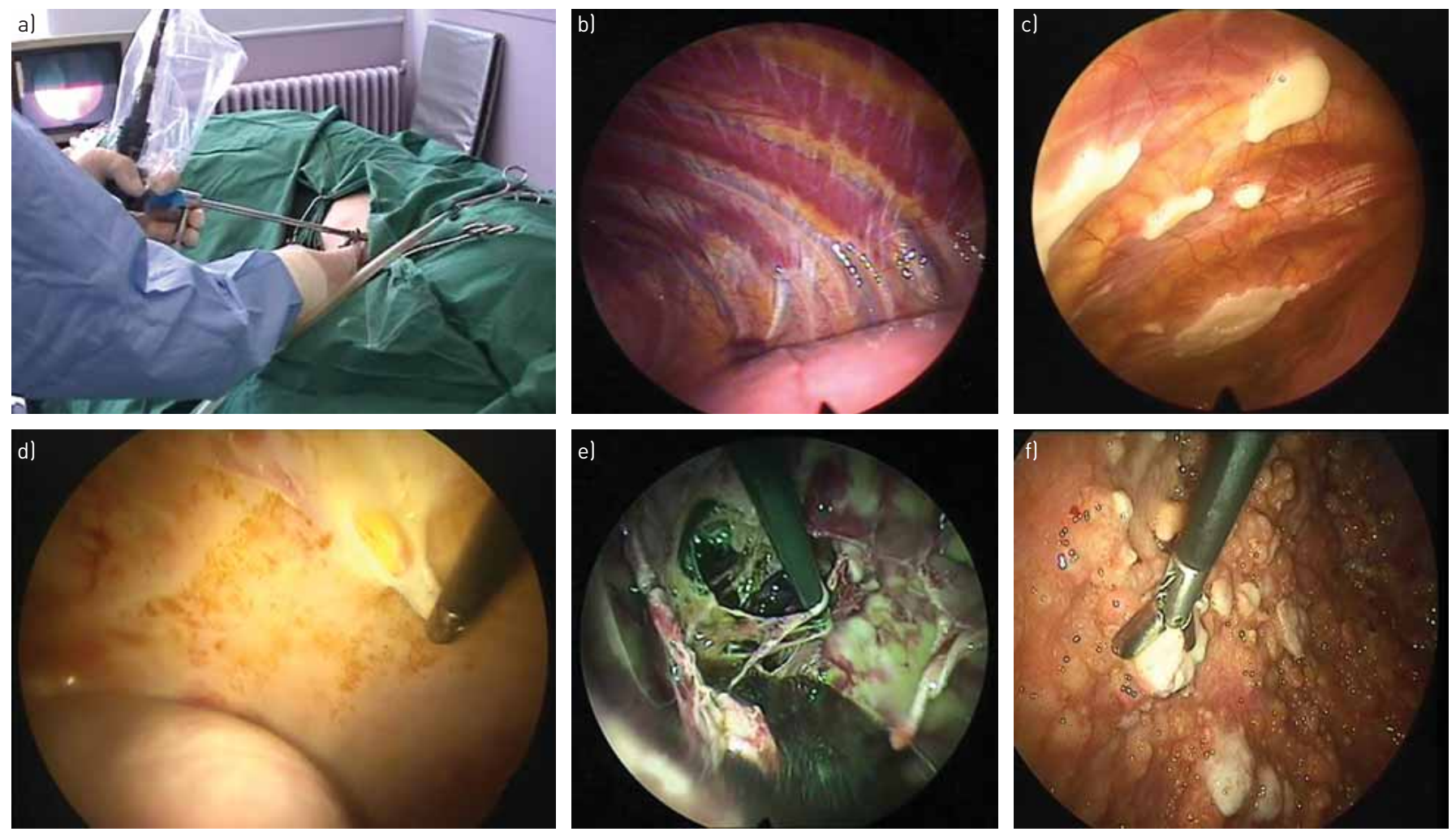

FIGURE 4 Medical thoracoscopy. a) Example of procedural room set-up for rigid thoracoscopy. b) Normal parietal pleura with clearly defined anatomy. c) Pleural plaque disease with typical "fried-egg" appearance overlying ribs. d) Diffuse parietal and visceral pleural thickening secondary to mesothelioma with two-port strip biopsy technique. e) Heavily septated pleural space using two-port technique to divide septations in context of intercurrent malignancy and infection. f) Widespread malignant pleural nodularity with two-port biopsy technique. 
is performed, facilitating both early discharge from hospital and long-term fluid control in the event of pleurodesis failing and/or the underlying lung being trapped [128]. This particular strategy needs further evaluation to determine the benefits and risks to patients alongside its economic credibility.

\section{The infected pleural space}

The standard management of pleural infection is centred on appropriate antibiotic choice and adequate evacuation of infected material from the thoracic cavity, most commonly via tube thoracostomy with or without intrapleural fibrinolytic therapy [129]. In a significant minority of cases, this approach fails and a rescue procedure is required. Traditionally, this has been the domain of thoracic surgeons using either video-assisted thoracoscopic surgery or open thoracotomy to perform adhesiolysis, decortication and washout. However, there are published data describing the use of medical thoracoscopy in this clinical scenario, both as a rescue therapy where conservative measures have failed or as a front-line intervention aimed at improving clearance through adhesiolysis and targeted drain placement [130-132]. These studies are small and observational only, and a RCT addressing the potential role of early medical thoracoscopy in pleural infection is needed to provide a definitive answer.

\section{Pneumothorax}

Recurrence rates in primary and secondary spontaneous pneumothorax have been reported as being as high as $50 \%$ in some studies; since these rates increase after the first recurrence, definitive treatment is recommended in those patients who suffer a second episode [40, 133]. More invasive management may also be indicated after one episode in specific scenarios such as prolonged air leak or where occupational regulations demand early treatment (e.g. pilots) [133]. Once more, whilst this has conventionally been the realm of the thoracic surgeon, medical thoracoscopy has been successfully used to treat patients with spontaneous pneumothorax. A RCT comparing medical thoracoscopic talc poudrage with standard conservative pleural drainage in 108 patients with primary spontaneous pneumothorax demonstrated improved clinical and economic outcomes for those patients who underwent thoracoscopy [134]. A smaller prospective case series of 41 patients with secondary spontaneous pneumothorax also reported favourably with low rates of recurrence and peri-procedural morbidity and mortality [135]. Whilst there are as yet no head-to-head trials comparing differing thoracoscopic management of spontaneous pneumothorax, data suggesting pleurodesis may be the key therapeutic intervention, and that chemical pleurodesis is equivalent to either mechanical abrasion and/or pleurectomy would appear to indicate a potential role for medical thoracoscopy in selected cases [136-138].

\section{Other conditions}

There are limited data relating to the use of medical thoracoscopy in the diagnosis and treatment of other conditions including recurrent symptomatic benign effusions, notably hepatic hydrothorax [139-141], sympathectomy for palmar hyperhidrosis $[142,143]$, and forceps lung biopsy for suspected interstitial lung disease [144]. Whilst these are worth mentioning as areas that might be explored further in future studies, thoracic surgeons continue to perform the majority of these procedures and there is no current evidence to suggest a definitive role in routine clinical practice for the interventional pulmonologist.

\section{Future directions}

The field of interventional pulmonology is continuing to grow and advance rapidly, with changes in the diagnosis and management of pleural disease at the forefront of these changes. The recognition of pleural disease as a distinct subspecialty within respiratory medicine has been central to this, and the next few years are likely to see an increasing number of centres offering rapid access clinics and procedural lists focused on diagnosis, treatment and outpatient management for this patient population $[1,145]$. In some respects, the early expansion of this field and, in particular, the delivery of interventional services has been driven by individual enthusiasts at a local level. However, with advanced interventions such as medical thoracoscopy and CPB being incorporated into guidelines as standard practice, the development of robust training standards to be applied on a national and international basis must be a priority [121]. Previously published guidelines $[111,146]$ are becoming progressively more outdated, and have been outstripped by the surge of interest in and provision of these services by physicians. It is consequently time for experts in the field to ensure that training and clinical practice are standardised with robust assessment and audit methodology to maintain a high and uniform level of care for patients.

Looking beyond the currently recruiting studies already outlined above that are expected to influence patient care within the next few years, there are a number of outstanding research questions still to be addressed. Developing the ambulatory day-case pathway for patients with pleural disease is one such area. IPCs have revolutionised outpatient management of recurrent symptomatic MPE; similarly, portable devices are being evaluated in the treatment of spontaneous pneumothorax, whilst the question of whether 
patients with pleural infection stratified as low risk [147] could be cared for on an outpatient basis with intermittent therapeutic thoracentesis or ambulatory drainage is still unanswered almost two decades after its initial proposal [148]. Even a significant intervention such as medical thoracoscopy may be feasible on a day-case basis in a carefully selected subset of patients [149]; its combination with IPC insertion for patients confirmed as having malignant pleural disease may provide a complete outpatient service without the need for even a single overnight stay in hospital [128].

As the expertise of interventional pulmonologists with thoracoscopy improves, it is likely that new techniques and indications for diagnostic and therapeutic procedures will be identified. A recently described novel three-dimensional thoracoscopic camera [150] may improve diagnostic yield and accessibility in patients with highly localised pleural disease. The use of semirigid thoracoscopes is becoming more common, although one criticism frequently raised is whether they permit sufficient diagnostic tissue to be obtained in cases where the parietal pleura is diffusely thickened and resistant to sampling. This might be overcome by cryoprobe biopsy [151, 152], although the routine use of this technique needs evaluation as part of a prospective multicentre trial. There have also been reports of the use of narrow-band imaging [153] and autofluorescence [154-156] during thoracoscopy as a means of identifying malignant change in the parietal pleura that is not otherwise macroscopically evident under white light inspection. Although promising, both of these remain techniques without a disease as long as it is unclear whether they can influence key clinical outcomes; in particular, the identification of patients who might otherwise be given a false-negative diagnosis of NSP.

\section{Conclusion}

With technological advances and greater availability of the techniques described in this article, the interested respiratory physician can now lay claim to a broader range of skills than at any other time, even those which may have previously been considered as uniquely radiological or surgical. For those wishing to focus on advanced pleural procedures, however, there is perhaps now a greater responsibility than ever before. Once skills are learned, there is a requirement to maintain and, if possible, improve standards, but perhaps more importantly, there must be recognition of the limits of one's own capabilities so as not to expose patients to unnecessary risk. Nonetheless, these are exciting times for both pulmonology as a whole and for pleural interventional practice specifically. Practitioners are now able to offer more to patients than ever before and, from a patient's perspective, this is ideal, limiting the need for repeated referrals, and both expediting and simplifying the often confusing journey towards diagnosis and treatment.

\section{References}

$1 \quad$ Hooper CE, Lee YC, Maskell NA. Setting up a specialist pleural disease service. Respirology 2010; 15: 1028-1036.

2 Hooper C, Maskell N. British Thoracic Society national pleural procedures audit 2010. Thorax 2011; 66: 636-637.

3 Young RL, Bhatnagar R, Mason ZD, et al. Evalution of an ambulatory pleural service: costs and benefits. Thorax 2013; 68: A42-A4A.

4 Davies HE, Nicholson JE, Rahman NM, et al. Outcome of patients with nonspecific pleuritis/fibrosis on thoracoscopic pleural biopsies. Eur J Cardiothorac Surg 2010; 38: 472-477.

5 Harris RJ, Kavuru MS, Mehta AC, et al. The impact of thoracoscopy on the management of pleural disease. Chest 1995; 107: 845-852.

6 Finley C, Clifton J, Fitzgerald JM, et al. Empyema: an increasing concern in Canada. Can Respir J 2008; 15 : $85-89$.

7 American Thoracic Society. Management of malignant pleural effusions. Am J Respir Crit Care Med 2000; 162: 1987-2001.

8 Nash E. Cancer Registration Statistics, England: 2013. Newport, Office for National Statistics, 2015.

9 Hallifax RJ, Corcoran JP, Ahmed A, et al. Physician-based ultrasound-guided biopsy for diagnosing pleural disease. Chest 2014; 146: 1001-1006.

10 Doelken P. Clinical implications of unexpandable lung due to pleural disease. Am J Med Sci 2008; 335: 21-25.

11 Lan RS, Lo SK, Chuang ML, et al. Elastance of the pleural space: a predictor for the outcome of pleurodesis in patients with malignant pleural effusion. Ann Intern Med 1997; 126: 768-774.

12 Roberts ME, Neville E, Berrisford RG, et al. Management of a malignant pleural effusion: British Thoracic Society Pleural Disease Guideline 2010. Thorax 2010; 65: Suppl. 2, ii32-ii40.

13 Light RW, Jenkinson SG, Minh V-D, et al. Observations on pleural fluid pressures as fluid is withdrawn during thoracentesis. Am Rev Respir Dis 1980; 121: 799-804.

14 Efthymiou CA, Masudi T, Thorpe JA, et al. Malignant pleural effusion in the presence of trapped lung. Five-year experience of PleurX tunnelled catheters. Interact Cardiovasc Thorac Surg 2009; 9: 961-964.

15 Wang JS, Tseng CH. Changes in pulmonary mechanics and gas exchange after thoracentesis on patients with inversion of a hemidiaphragm secondary to large pleural effusion. Chest 1995; 107: 1610-1614.

16 Estenne M, Yernault JC, De Troyer A. Mechanism of relief of dyspnea after thoracocentesis in patients with large pleural effusions. Am J Med 1983; 74: 813-819.

17 Matsuura Y, Nomimura T, Murakami H, et al. Clinical analysis of reexpansion pulmonary edema. Chest 1991; 100: $1562-1566$.

18 Salamonsen MR, Lo AK, Ng AC, et al. Novel use of pleural ultrasound can identify malignant entrapped lung prior to effusion drainage. Chest 2014; 146: 1286-1293. 
Pannu J, DePew ZS, Mullon JJ, et al. Impact of pleural manometry on the development of chest discomfort during thoracentesis: a symptom-based study. J Bronchology Interv Pulmonol 2014; 21: 306-313.

Feller-Kopman D, Berkowitz D, Boiselle P, et al. Large-volume thoracentesis and the risk of reexpansion pulmonary edema. Ann Thorac Surg 2007; 84: 1656-1661.

Heidecker J, Huggins JT, Sahn SA, et al. Pathophysiology of pneumothorax following ultrasound-guided thoracentesis. Chest 2006; 130: 1173-1184.

Feller-Kopman D. Point: should pleural manometry be performed routinely during thoracentesis? Yes. Chest 2012; 141: 844-845.

Folch E, Mahajan A, Majid A. Pleural manometry: ready for prime time. J Bronchology Interv Pulmonol 2013; 20: 297-298.

Maldonado F, Mullon JJ. Counterpoint: should pleural manometry be performed routinely during thoracentesis? No. Chest 2012; 141: 846-848.

Lee HJ, Yarmus L, Kidd D, et al. Comparison of pleural pressure measuring instruments. Chest 2014; 146 : 1007-1012.

Salamonsen M, Ware R, Fielding D. A new method for performing continuous manometry during pleural effusion drainage. Respiration 2014; 88: 61-66.

Boshuizen RC, Sinaasappel M, Vincent AD, et al. Pleural pressure swing and lung expansion after malignant pleural effusion drainage: the benefits of high-temporal resolution pleural manometry. J Bronchology Interv Pulmonol 2013; 20: 200-205.

Havelock T, Teoh R, Laws D, et al. Pleural procedures and thoracic ultrasound: British Thoracic Society Pleural Disease Guideline 2010. Thorax 2010; 65: Suppl. 2, ii61-ii76.

National Patient Safety Agency. Rapid Response Report NPSA/2008/RRR003: Risks of Chest Drain Insertion. London, National Health Service, 2008.

Hooper C, Lee YC, Maskell N. Investigation of a unilateral pleural effusion in adults: British Thoracic Society Pleural Disease Guideline 2010. Thorax 2010; 65: Suppl. 2, ii4-i17. departmental scanning. Respir Med 2010; 104: 612-614.

Board of the Faculty of Clinical Radiology. Ultrasound Training Recommendations for Medical and Surgical Specialties https://www.rcr.ac.uk/sites/default/files/publication/BFCR(12)17_ultrasound_training.pdf

Mayo PH, Beaulieu Y, Doelken P, et al. American College of Chest Physicians/La Société de Réanimation de Langue Française statement on competence in critical care ultrasonography. Chest 2009; 135: 1050-1060.

European Federation of Societies for Ultrasound in Medicine and Biology. Minimum training requirements for the practice of medical ultrasound in Europe. Appendix 11: Thoracic ultrasound. www.efsumb.org/guidelines/ 2009-04-14apx11.pdf Date last updated: October 2008

Diacon AH, Brutsche MH, Soler M. Accuracy of pleural puncture sites: a prospective comparison of clinical examination with ultrasound. Chest 2003; 123: 436-441. meta-analysis. Arch Intern Med 2010; 170: 332-339. patients undergoing thoracentesis and paracentesis. Chest 2013; 143: 532-538.

Salamonsen M, Dobeli K, McGrath D, et al. Physician-performed ultrasound can accurately screen for a vulnerable intercostal artery prior to chest drainage procedures. Respirology 2013; 18: 942-947.

Tunnicliffe G, Draper A. A pilot study of a digital drainage system in pneumothorax. BMJ Open Respir Res 2014; 1: e000033.

Bintcliffe OJ, Hallifax RJ, Edey A, et al. Spontaneous pneumothorax: time to rethink management? Lancet Respir Med 2015; 3: 578-588.

Laskawiec-Szkonter M. Randomised ambulatory management of primary pneumothorax (RAMPP). www.isrctn. com/ISRCTN79151659 Date last updated: August 21, 2015.

Sciurba FC, Ernst A, Herth FJ, et al. A randomized study of endobronchial valves for advanced emphysema. N Engl J Med 2010; 363: 1233-1244.

Spiration Inc. Spiration Valves Against Standard Therapy (VAST) https://clinicaltrials.gov/ct2/show/NCT02382614 Date last updated: February 29, 2016.

Rahman NM, Maskell NA, West A, et al. Intrapleural use of tissue plasminogen activator and DNase in pleural infection. N Engl J Med 2011; 365: 518-526.

Maskell NA, Davies CW, Nunn AJ, et al. U.K. controlled trial of intrapleural streptokinase for pleural infection. N Engl J Med 2005; 352: 865-874.

Piccolo F, Pitman N, Bhatnagar R, et al. Intrapleural tPA and DNase for pleural infection: an effective and safe alternative to surgery. Ann Am Thorac Soc 2014; 11: 1419-1425.

Thomas R, Piccolo F, Miller D, et al. Intrapleural fibrinolysis for the treatment of indwelling pleural catheter-related symptomatic loculations: a multicenter observational study. Chest 2015; 148: 746-751.

Hunt I, Teh E, Southon R, et al. Using non-steroidal anti-inflammatory drugs (NSAIDs) following pleurodesis. Interact Cardiovasc Thorac Surg 2007; 6: 102-104.

Rahman N, Pepperell J, Rehal S, et al. Primary result of the 1st Therapeutic Interventions in Malignant Effusion (TIME1) trial: a $2 \times 2$ factorial, randomised trial of chest tube size and analgesic strategy for pleurodesis in malignant pleural effusion. Thorax 2015; 70: Suppl. 3, A15-A16. drainage before tetracycline pleurodesis in the treatment of malignant pleural effusions. Thorax 1994; 49: 23-25. Fysh ET, Waterer GW, Kendall PA, et al. Indwelling pleural catheters reduce inpatient days over pleurodesis for malignant pleural effusion. Chest 2012; 142: 394-400.

Davies HE, Mishra EK, Kahan BC, et al. Effect of an indwelling pleural catheter vs chest tube and talc pleurodesis for relieving dyspnea in patients with malignant pleural effusion: the TIME2 randomized controlled trial. JAMA 2012; 307: 2383-2389.

Fysh E, Geelhoed E, Kendall P, et al. Indwelling pleural catheters significantly reduced hospital admissions in patients with malignant pleural effusions. Respirology 2011; 16: 63. 
Thornton RH, Miller Z, Covey AM, et al. Tunneled pleural catheters for treatment of recurrent malignant pleural effusion following failed pleurodesis. J Vasc Interv Radiol 2010; 21: 696-700.

Pien GW, Gant MJ, Washam CL, et al. Use of an implantable pleural catheter for trapped lung syndrome in patients with malignant pleural effusion. Chest 2001; 119: 1641-1646.

Qureshi RA, Collinson SL, Powell RJ, et al. Management of malignant pleural effusion associated with trapped lung syndrome. Asian Cardiovasc Thorac Ann 2008; 16: 120-123.

Tremblay A, Mason C, Michaud G. Use of tunnelled catheters for malignant pleural effusions in patients fit for pleurodesis. Eur Respir J 2007; 30: 759-762.

Bhatnagar R, Maskell N. Indwelling pleural catheters for ambulatory out-patient care: a price worth paying? Respiration 2013; 86: 181-182.

Penz ED, Mishra EK, Davies HE, et al. Comparing cost of indwelling pleural catheter $v s$ talc pleurodesis for malignant pleural effusion. Chest 2014; 146: 991-1000.

Olden AM, Holloway R. Treatment of malignant pleural effusion: PleuRx catheter or talc pleurodesis? A cost-effectiveness analysis. J Palliat Med 2010; 13: 59-65.

Puri V, Pyrdeck TL, Crabtree TD, et al. Treatment of malignant pleural effusion: a cost-effectiveness analysis. Ann Thorac Surg 2012; 94: 374-379.

effusions. Am J Respir Crit Care 2011; 183.

Shafiq M, Frick KD, Lee H, et al. Management of malignant pleural effusion: a cost-utility analysis. J Bronchology Interv Pulmonol 2015; 22: 215-225.

Van Meter ME, McKee KY, Kohlwes RJ. Efficacy and safety of tunneled pleural catheters in adults with malignant pleural effusions: a systematic review. J Gen Intern Med 2011; 26: 70-76.

Fysh ET, Tremblay A, Feller-Kopman D, et al. Clinical outcomes of indwelling pleural catheter-related pleural infections: an international multicenter study. Chest 2013; 144: 1597-1602.

Tremblay A, Michaud G. Single-center experience with 250 tunnelled pleural catheter insertions for malignant pleural effusion. Chest 2006; 129: 362-368.

Rosenstengel A, Tremblay A, Fysh E, et al. Pleural infections associated with indwelling pleural catheters (IPC). Chest 2012; 142: Suppl., 487A.

Suzuki K, Servais EL, Rizk NP, et al. Palliation and pleurodesis in malignant pleural effusion: the role for tunnelled pleural catheters. J Thorac Oncol 2011; 6: 762-767.

Mekhaiel E, Kashyap R, Maldonado F, et al. Incidence of infection among patients on chemotherapy with tunneled indwelling pleural catheters. Chest 2012; 142: Suppl., 523A.

Mullan J, Maldonado F. Use of tunneled indwelling pleural catheters for palliation of nonmalignant pleural effusions. Chest 2011; 140: Suppl., 996A.

Mekhaiel E, Kashyap R, Mullon JJ, et al. Infections associated with tunnelled indwelling pleural catheters in patients undergoing chemotherapy. J Bronchology Interv Pulmonol 2013; 20: 299-303.

Morel A, Mishra E, Medley L, et al. Chemotherapy should not be withheld from patients with an indwelling pleural catheter for malignant pleural effusion. Thorax 2011; 66: 448-449.

Almeida FA, Bruno DS, Faiz S, et al. Hemothorax treated with indwelling tunneled pleural catheter: are all hemothoraces the same? J Bronchology Interv Pulmonol 2011; 18: 261-264.

Davies HE, Rahman NM, Parker RJ, et al. Use of indwelling pleural catheters for chronic pleural infection. Chest 2008; 133: 546-549.

Bintcliffe OJ, Arnold DT, Maskell NA. Indwelling pleural catheters for benign pleural effusions. Curr Respir Care Rep 2014; 3: 61-70.

Kataoka H. Pericardial and pleural effusions in decompensated chronic heart failure. Am Heart J 2000; 139: 918-923.

Strauss RM, Boyer TD. Hepatic hydrothorax. Semin Liver Dis 1997; 17: 227-232. 889-891. Bhatnagar R, Reid ED, Corcoran JP, et al. Indwelling pleural catheters for non-malignant effusions: a multicentre review of practice. Thorax 2014; 69: 959-961.

Maskell N. REDUCE Trial: A randomised controlled trial evaluating the efficacy of indwelling pleural catheters in persistent non-malignant symptomatic pleural effusions. www.isrctn.com/ISRCTN66354436 Date last updated: July 312015 .

Maskell N. The efficacy of indwelling pleural catheter placement versus IPC placement PLUS sclerosant (talc) in patients with malignant pleural effusions managed exclusively as out-patients 2012. www.isrctn.com/ ISRCTN73255764 Date last updated: January 18, 2016.

Ahmed L, Ip H, Rao D, et al. Talc pleurodesis through indwelling pleural catheters for malignant pleural effusions: retrospective case series of a novel clinical pathway. Chest 2014; 146: e190-e194.

Barrett D, Conner M, Bonnie S, et al. Double-blind randomized comparison of bleomycin \& doxycycline adminstered via an indwelling pleural catheter for malignant pleural effusions (MPE). Am J Respir Crit Care 2002; 8: Suppl., A606.

Rahman NM, Davies HE, Salzberg M, et al. Use of lipoteichoic acid-T for pleurodesis in malignant pleural effusion: a phase I toxicity and dose-escalation study. Lancet Oncol 2008; 9: 946-952.

Jones DR, Taylor MD, Petroni GR, et al. Phase I trial of intrapleural docetaxel administered through an implantable catheter in subjects with a malignant pleural effusion. J Thorac Oncol 2010; 5: 75-81.

Sterman DH, Recio A, Carroll RG, et al. A phase I clinical trial of single-dose intrapleural IFN- $\beta$ gene transfer for malignant pleural mesothelioma and metastatic pleural effusions: high rate of antitumor immune responses. Clin Cancer Res 2007; 13: 4456-4466.

Tremblay A, Dumitriu S, Stather DR, et al. Use of a drug eluting pleural catheter for pleurodesis. Exp Lung Res 2012; 38: 475-482.

Tremblay A, Stather DR, Kelly MM. Effect of repeated administration of low-dose silver nitrate for pleurodesis in a rabbit model. Respirology 2011; 16: 1070-1075.

Light RW. Clinical practice. Pleural effusion. N Engl J Med 2002; 346: 1971-1977. 
Porcel JM, Esquerda A, Vives M, et al. Etiology of pleural effusions: analysis of more than 3,000 consecutive thoracenteses. Arch Bronconeumol 2014; 50: 161-165.

Clive AO, Kahan BC, Hooper CE, et al. Predicting survival in malignant pleural effusion: development and validation of the LENT prognostic score. Thorax 2014; 69: 1098-1104.

Prakash UB, Reiman HM. Comparison of needle biopsy with cytologic analysis for the evaluation of pleural effusion: analysis of 414 cases. Mayo Clin Proc 1985; 60: 158-164.

Garcia LW, Ducatman BS, Wang HH. The value of multiple fluid specimens in the cytological diagnosis of malignancy. Mod Pathol 1994; 7: 665-668.

Abrams LD. A pleural-biopsy punch. Lancet 1958; 1: 30-31.

Cope C. New pleural biopsy needle; preliminary study. JAMA 1958; 167: 1107-1108.

Diacon AH, Van de Wal BW, Wyser C, et al. Diagnostic tools in tuberculous pleurisy: a direct comparative study. Eur Respir J 2003; 22: 589-591.

Chang DB, Yang PC, Luh KT, et al. Ultrasound-guided pleural biopsy with Tru-Cut needle. Chest 1991; 100: 1328-1333.

McLeod DT, Ternouth I, Nkanza N. Comparison of the Tru-cut biopsy needle with the Abrams punch for pleural biopsy. Thorax 1989; 44: 794-796.

Maskell NA, Gleeson FV, Davies RJ. Standard pleural biopsy versus CT-guided cutting-needle biopsy for diagnosis of malignant disease in pleural effusions: a randomised controlled trial. Lancet 2003; 361: 1326-1330. Rahman NM, Gleeson FV. Image-guided pleural biopsy. Curr Opin Pulm Med 2008; 14: 331-336.

Adams RF, Gleeson FV. Percutaneous image-guided cutting-needle biopsy of the pleura in the presence of a suspected malignant effusion. Radiology 2001; 219: 510-514.

Benamore RE, Scott K, Richards CJ, et al. Image-guided pleural biopsy: diagnostic yield and complications. Clin Radiol 2006; 61: 700-705.

Diacon AH, Schuurmans MM, Theron J, et al. Safety and yield of ultrasound-assisted transthoracic biopsy performed by pulmonologists. Respiration 2004; 71: 519-522.

Sconfienza LM, Mauri G, Grossi F, et al. Pleural and peripheral lung lesions: comparison of US- and CT-guided biopsy. Radiology 2013; 266: 930-935.

Corcoran JP, Psallidas I, Ross CL, et al. Always worth another look? Thoracic ultrasonography before, during, and after pleural intervention. Ann Am Thorac Soc 2016; 13: 118-121.

Botana Rial M, Briones Gomez A, Ferrando Gabarda JR, et al. Tru-cut needle pleural biopsy and cytology as the initial procedure in the evaluation of pleural effusion. Arch Bronconeumol 2014; 50: 313-317.

Koegelenberg CF, Irusen EM, von Groote-Bidlingmaier F, et al. The utility of ultrasound-guided thoracentesis and pleural biopsy in undiagnosed pleural exudates. Thorax 2015; 70: 995-997.

Gordon SAV. Clinical reports of rare cases, occurring in the Whitworth and Hardwicke Hospitals. The Dublin Quart J Med Sci 1866; 41: 83-99.

Jacobaeus HC. Uber die moglichkeit die zystoskopie bei Untersuchung seroser hohlungen anzuwenden. Munch Med Wochenschr 1910; 57: 2090-2092.

Jacobaeus HC. The cauterization of adhesions in artificial pneumothorax treatment of pulmonary tuberculosis under thoracoscopic control. Proc R Soc Med 1923; 16: 45-62.

Rahman NM, Ali NJ, Brown G, et al. Local anaesthetic thoracoscopy: British Thoracic Society Pleural Disease Guideline 2010. Thorax 2010; 65: Suppl. 2, ii54-ii60.

Astoul P, Maldonado F. Anesthetic drugs managed by pulmonologists during medical thoracoscopy: one size does not fit all! Respiration 2014; 88: 265-267.

Medford AR, Agrawal S, Bennett JA, et al. Thoracic ultrasound prior to medical thoracoscopy improves pleural access and predicts fibrous septation. Respirology 2010; 15: 804-808.

Shojaee S, Argento AC. Ultrasound-guided pleural access. Semin Respir Crit Care Med 2014; 35: 693-705.

Marchetti G, Valsecchi A, Indellicati D, et al. Ultrasound-guided medical thoracoscopy in the absence of pleural effusion. Chest 2015; 147: 1008-1012.

Corcoran JP, Psallidas I, Hallifax RJ, et al. Ultrasound-guided pneumothorax induction prior to local anaesthetic thoracoscopy. Thorax 2015; 70: 906-908.

Trisolini R, Gasparini S, Patelli M. Is rapid on-site evaluation during bronchoscopy useful? Expert Rev Respir Med 2013; 7: 439-441.

Khan MA, Ambalavanan S, Thomson D, et al. A comparison of the diagnostic yield of rigid and semirigid thoracoscopes. J Bronchology Interv Pulmonol 2012; 19: 98-101.

Rozman A, Camlek L, Marc-Malovrh M, et al. Rigid versus semi-rigid thoracoscopy for the diagnosis of pleural disease: a randomized pilot study. Respirology 2013; 18: 704-710.

Dhooria S, Singh N, Aggarwal AN, et al. A randomized trial comparing the diagnostic yield of rigid and semirigid thoracoscopy in undiagnosed pleural effusions. Respir Care 2014; 59: 756-764.

Feller-Kopman D, Yarmus L. Training in interventional pulmonology. Semin Respir Crit Care Med 2014; 35: 631-635.

Venekamp LN, Velkeniers B, Noppen M. Does 'idiopathic pleuritis' exist? Natural history of non-specific pleuritis diagnosed after thoracoscopy. Respiration 2005; 72: 74-78.

Metintas M, Ak G, Cadirci O, et al. Outcome of patients diagnosed with fibrinous pleuritis after medical thoracoscopy. Respir Med 2012; 106: 1177-1183.

4 de Campos JR, Vargas FS, de Campos Werebe E, et al. Thoracoscopy talc poudrage: a 15-year experience. Chest 2001; 119: 801-806.

5 Yim AP, Chan AT, Lee TW, et al. Thoracoscopic talc insufflation versus talc slurry for symptomatic malignant pleural effusion. Ann Thorac Surg 1996; 62: 1655-1658.

Dresler CM, Olak J, Herndon JEII, et al. Phase III intergroup study of talc poudrage vs talc slurry sclerosis for malignant pleural effusion. Chest 2005; 127: 909-915.

Bhatnagar R, Laskawiec-Szkonter M, Piotrowska HE, et al. Evaluating the efficacy of thoracoscopy and talc poudrage versus pleurodesis using talc slurry (TAPPS trial): protocol of an open-label randomised controlled trial. BMJ Open 2014; 4: e007045.

8 Reddy C, Ernst A, Lamb C, et al. Rapid pleurodesis for malignant pleural effusions: a pilot study. Chest 2011; 139: 1419-1423. 
Davies HE, Davies RJ, Davies CW. Management of pleural infection in adults: British Thoracic Society Pleural Disease Guideline 2010. Thorax 2010; 65: Suppl. 2, ii41-ii53.

Brutsche MH, Tassi GF, Gyorik S, et al. Treatment of sonographically stratified multiloculated thoracic empyema by medical thoracoscopy. Chest 2005; 128: 3303-3309.

Ravaglia C, Gurioli C, Tomassetti S, et al. Is medical thoracoscopy efficient in the management of multiloculated and organized thoracic empyema? Respiration 2012; 84: 219-224.

Soler M, Wyser C, Bolliger CT, et al. Treatment of early parapneumonic empyema by "medical" thoracoscopy Schweiz Med Wschr 1997; 127: 1748-1753.

MacDuff A, Arnold A, Harvey J. Management of spontaneous pneumothorax: British Thoracic Society Pleural Disease Guideline 2010. Thorax 2010; 65: Suppl. 2, ii18-ii31.

Tschopp JM, Boutin C, Astoul P, et al. Talcage by medical thoracoscopy for primary spontaneous pneumothorax is more cost-effective than drainage: a randomised study. Eur Respir J 2002; 20: 1003-1009.

prevention in advanced COPD. Chest 2004; 125: 1315-1320.

Cardillo G, Facciolo F, Giunti R, et al. Videothoracoscopic treatment of primary spontaneous pneumothorax: a 6-year experience. Ann Thorac Surg 2000; 69: 357-361.

Horio $\mathrm{H}$, Nomori $\mathrm{H}$, Kobayashi $\mathrm{R}$, et al. Impact of additional pleurodesis in video-assisted thoracoscopic bullectomy for primary spontaneous pneumothorax. Surg Endosc 2002; 16: 630-634.

Sepehripour AH, Nasir A, Shah R. Does mechanical pleurodesis result in better outcomes than chemical pleurodesis for recurrent primary spontaneous pneumothorax? Interact Cardiovasc Thorac Surg 2012; 14: 307-311.

Aelony Y, King R, Boutin C. Thoracoscopic talc poudrage pleurodesis for chronic recurrent pleural effusions Ann Intern Med 1991; 115: 778-782.

Milanez de Campos JR, Filho LO, de Campos Werebe E, et al. Thoracoscopy and talc poudrage in the management of hepatic hydrothorax. Chest 2000; 118: 13-17.

Ferrante D, Arguedas MR, Cerfolio RJ, et al. Video-assisted thoracoscopic surgery with talc pleurodesis in the management of symptomatic hepatic hydrothorax. Am J Gastroenterol 2002; 97: 3172-3175. treatment of essential hyperhidrosis: short-term results in 100 patients. J Laparoendosc Surg 1996; 6: 151-159.

Tang $\mathrm{H}, \mathrm{Wu} \mathrm{B}, \mathrm{Xu} \mathrm{Z}$, et al. A new surgical procedure for palmar hyperhidrosis: is it possible to perform endoscopic sympathectomy under deep sedation without intubation? Eur J Cardiothorac Surg 2014; 46: 286-290.

Vansteenkiste J, Verbeken E, Thomeer M, et al. Medical thoracoscopic lung biopsy in interstitial lung disease: a prospective study of biopsy quality. Eur Respir J 1999; 14: 585-590.

Bhatnagar R, Maskell N. Developing a 'pleural team' to run a reactive pleural service. Clin Med 2013; 13: 452-456.

Ernst A, Silvestri GA, Johnstone D. Interventional pulmonary procedures: guidelines from the American College of Chest Physicians. Chest 2003; 123: 1693-1717.

Rahman NM, Kahan BC, Miller RF, et al. A clinical score (RAPID) to identify those at risk for poor outcome at presentation in patients with pleural infection. Chest 2014; 145: 848-855.

Sasse S, Nguyen T, Teixeira LR, et al. The utility of daily therapeutic thoracentesis for the treatment of early empyema. Chest 1999; 116: 1703-1708.

DePew ZS, Wigle D, Mullon JJ, et al. Feasibility and safety of outpatient medical thoracoscopy at a large tertiary medical center: a collaborative medical-surgical initiative. Chest 2014; 146: 398-405.

Arias S, Semaan R, Lee H, et al. Tridimensional medical thoracoscopy. Ann Am Thorac Soc 2015; 12: 945-947.

Thomas R, Karunarathne S, Jennings B, et al. Pleuroscopic cryoprobe biopsies of the pleura: a feasibility and safety study. Respirology 2015; 20: 327-332.

Rozman A, Camlek L, Marc Malovrh M, et al. Feasibility and safety of parietal pleural cryobiopsy during semi-rigid thoracoscopy. Clin Respir J 2014 [In press DOI: 10.1111/cri.12256].

Ishida A, Ishikawa F, Nakamura M, et al. Narrow band imaging applied to pleuroscopy for the assessment of vascular patterns of the pleura. Respiration 2009; 78: 432-439.

Chrysanthidis MG, Janssen JP. Autofluorescence videothoracoscopy in exudative pleural effusions: preliminary results. Eur Respir J 2005; 26: 989-992.

Eur J Cardiothorac Surg 2012; 41: 649-652.

Wang F, Wang Z, Tong Z, et al. A pilot study of autofluorescence in the diagnosis of pleural disease. Chest 2015; 147: 1395-1400. 